\title{
A Case of Ring Chromosome 18 with Single Umbilical Artery Detected During Prenatal Period
}

\author{
Nazan Eras \\ Department of Medical Genetics, Faculty of Medicine, Mersin University, Mersin, Turkey
}

\section{Established Facts}

- Ring chromosome 18 is a rare genetic condition that is caused by the loss of genetic material near the end of the short and the long arm of chromosome 18.

- The single umbilical artery due to primary agenesis may be an isolated finding or is associated with chromosomal anomalies and serious malformations.

\section{Novel Insights}

- Loss of genetic material on each arm of chromosome 18 may lead to different phenotypes. The present case contributes to the identification of the genotype-phenotype correlation of ring chromosome 18.

\section{Keywords}

Dysmorphic facial features $\cdot$ Rare disease $\cdot$ Ring chromosome 18 - Single umbilical artery · Variable phenotype

\begin{abstract}
Fetuses with a single umbilical artery have a risk of increased chromosomal anomalies and congenital malformations. Ring chromosomes are rare and the phenotypic and clinical characteristics of affected individuals show great variability depending on the quantity of the lost critical genes or gains during the formation of the ring or due to mitotic instability. Ring chromosome 18 [r(18)] is characterized by short stature, craniofacial dysmorphism, mental and motor retardation, autoimmune disorders, extremity anomalies, dermal lesions, structural heart malformations, and kidney abnor-
\end{abstract}

malities. In this study, the clinical findings of a female patient who had a single umbilical artery in the prenatal period and was diagnosed as de novo $r(18)$ by molecular karyotype analysis were compared with those in the literature. A detailed ultrasonographic examination of the fetus with a single umbilical artery may enable the detection of additional anomalies and thus the early diagnosis of chromosomal anomalies may be possible with prenatal genetic analysis.

(C) 2020 S. Karger AG, Basel

\section{Introduction}

The estimated frequency of ring chromosomes which constitute a small percentage of all structural chromosome anomalies is between 1/30,000 and 1/60,000 [Kosztolányi, 2009]. Structurally, ring chromosomes are di-

$\begin{aligned} & \text { karger@karger.com } \\ & \text { www.karger.com/msy }\end{aligned}$
Karger ${ }^{\prime /}$


vided into 2 groups: the ring chromosome 18 [r(18)] replaces one of the normal homologs or supernumerary, where the ring is additional to 2 normal copies of the chromosome [van der Veken et al., 2010; Mazzaschi et al., 2011]. During mitosis, ring chromosomes can exhibit unstable behavior and lead to further chromosomal abnormalities. Transmission of these unstable chromosomes may lead to possible de novo formation of a ring chromosome in the next generation, in addition to the presence of a normal cell line, accounting for a mosaic karyotype both in the parent and the offspring [Rajesh et al., 2011]. While in around 99\% of the cases the ring occurs de novo, approximately $1 \%$ of the cases exhibits hereditary transmission [Kosztolányi, 2009]. Males with ring chromosomes have oligospermia and azoospermia because of the matching and separation during meiosis and cannot transmit the ring chromosomes to the next generation as they lose the majority of the gametes during meiosis. Loss of gametes during meiosis occurs in different degrees depending on the ring chromosome load of an individual, stability of the ring, degree of mosaicism in the testicles, and unpredictable outcomes during meiosis [Rajesh et al., 2011]. On the other hand, as the gametogenesis is not affected, females with a ring chromosome may transmit it to the next generation. Therefore, it is believed that the majority of the hereditary ring chromosomes have a maternal origin [Rajesh et al., 2011; Caba et al., 2012].

In most cases, mosaic ring chromosomes are found; less often loss of the ring, double-sized rings, or multiple copies of the ring are observed [Carreira et al., 2007]. Structurally, the complete ring chromosomes occur as a result of the fusion of the telomeres at the ends of chromosomes without genetic material loss. The incomplete ring chromosomes may occur through breaks in the chromosome arms and fusion of the proximal broken ends, leading to loss of distal material. Alternatively, a supernumerary ring chromosome occurs together with 2 normal homologous chromosomes, resulting in partial trisomies or duplications [Pezzolo et al., 1993; Hu et al., 2018]. The phenotypic and clinical characteristics of individuals with ring chromosomes may change prominently depending on the quantity of the lost genes or gains during the forming of the ring or mitotic instability [Rossi et al., 2008; Jain et al., 2011]. r(18), first described by Gropp et al. [1964], is a rare type of intrachromosomal structural anomaly [Jacobs et al., 1975]. The clinical profile of $r(18)$ is characterized by short stature, microcephaly, mental and motor retardation, craniofacial dysmorphism, extremity anomalies, dermal lesions, genital anomalies, structural heart malformations, and kidney defects [Jain et al., 2011; Spreiz et al., 2013; Carter et al., 2015]. Other possible manifestations are epilepsy, insulin-dependent diabetes mellitus, autoimmune thyroid disease, growth hormone deficiency, hyperthyroidism, IgA deficiency, autoimmune polyglandular endocrinopathy, and rheumatoid arthritis [Dacou-Voutetakis et al., 1999; Jain et al., 2011; Lo-Castro et al., 2011; Chau et al., 2017]. It has been suggested that a mosaic ring 18 can cause Pitt-Hopkins syndrome (PTHS). In cases of mosaic ring 18 associated PTHS, it was reported that clinical symptoms of PTHS were characteristic facial gestalt, episodic hyperventilation, and severe developmental delay with absent speech [Takenouchi et al., 2012]. In this report, a case of $\mathrm{r}(18)$ with single umbilical artery and deletions involving 18p11.32p11.31 and $18 \mathrm{q} 21.31 \mathrm{q} 23$ is described and clinical findings of the present case are compared with data given in the literature.

\section{Case Report}

A single umbilical artery and nuchal translucency were determined by obstetric ultrasonography during prenatal follow-up. The patient was delivered by a cesarean section due to breech presentation in the 39th week as the second living child (second pregnancy) of a healthy 36-year-old mother married to a healthy 51-year-old father. Mother and father are first-degree relatives. The mother had no other health problems except for severe nausea during pregnancy. Birth weight was 3,190 g (25-50th percentiles), height $45 \mathrm{~cm}$ (10-25th percentiles), and head circumference was $34 \mathrm{~cm}$ (10-25th percentiles). The patient remained in an incubator for 52 days due to dyspnea, hypotonicity, stridor due to laryngomalacia, oral secretions, and vomiting. The echocardiographic examination, performed when the child was 4 days old, showed an atrial septal defect, patent ductus arteriosus, pulmonary hypertension, and dilatation in the ascending aorta. The patient underwent phototherapy because of jaundice during the hospital stay. Bilateral stenosis in the external auditory canals and hearing loss were detected during the ear-nose-throat examination performed at birth and second month. Oral feeding was initiated when the baby was 2 months old. Amino acid and acylcarnitine profiles analyzed using the tandem mass spectrometry method were normal. As the free thyroxine (fT4) level was low (0.91 $\mathrm{ng} / \mathrm{dL}$ ) and the thyroid-stimulating hormone (TSH) level was high $(30.69 \mu \mathrm{IU} / \mathrm{mL})$, treatment for hypothyroidism was initiated with Euthyrox. After Euthyrox treatment, the levels of T4 and TSH were normalized. The diameters of the lymph nodes and parenchymal echoes were normal, and no nodule was detected in the ultrasonographic examination of the thyroid gland. The liver, gallbladder, spleen, and kidneys were normal in the abdominal ultrasound examination. However, vesicoureteral reflux was determined. The results of the transfontanelle ultrasound and bilateral pelvic ultrasound examinations were normal. Brain MRI showed benign external hydrocephaly and fluid intensities as well 
Fig. 1. a Frontal view of the patient at the age of 1 year: micrognathia, hypertelorism, flattened nasal root, flat philtrum, anteverted nares, broad nasal bridge, upslanting palpebral fissure, esotropia, flattened midface, telecanthus, and sparse eyebrows. $\mathbf{b}$ Clinical appearance of overlapping toes.
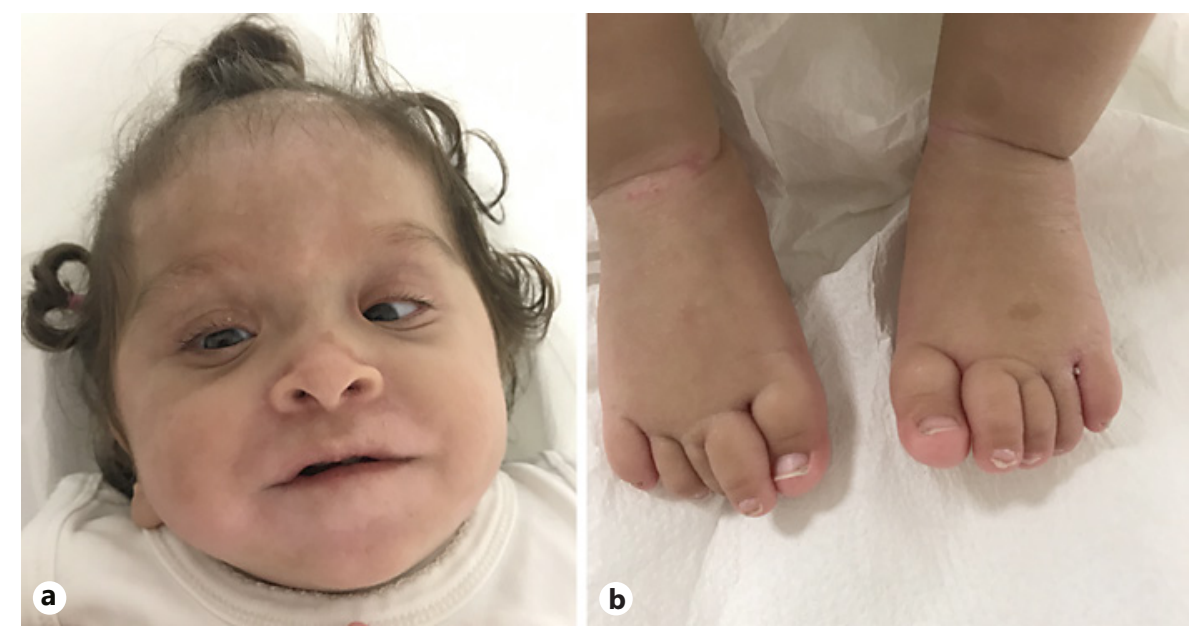

as edematous changes in the parietal subdermal tissue. Five months after birth, the patient was brought to the hospital due to skin eruptions on the cheeks. The multiple and nonfading macular skin eruptions spread over the body and the child was admitted to the intensive care unit since respiratory distress developed. The patient was diagnosed with eczema herpeticum, and mechanic ventilation was necessary because of respiratory arrest during the treatment. The patient experienced the first epileptic attack at 7 months, and an antiepileptic treatment with Keppra $(25 \mathrm{mg} / \mathrm{kg}$ BID) was initiated. The Denver II Developmental Screening Test was performed when the patient was 8 months old. The test showed delays in language development, fine motor development, and gross motor fields; the overall test result was abnormal. The growth hormone level of the patient was normal (height 10-25th percentiles). On the other hand, the patient's IgG, IgM, and IgA levels were low, and the IgE level was high. The IgG, IgM, and IgA levels were $510 \mathrm{mg} / \mathrm{dL}$ (reference range: $751-1,560 \mathrm{mg} / \mathrm{dL}$ ), 42 $\mathrm{mg} / \mathrm{dL}$ (reference range: $46-304 \mathrm{mg} / \mathrm{dL}$ ), and $16.6 \mathrm{mg} / \mathrm{dL}$ (reference range: $82-453 \mathrm{mg} / \mathrm{dL}$ ), respectively; while the IgE level was $91.73 \mathrm{IU} / \mathrm{mL}$ (reference range: $0-15 \mathrm{IU} / \mathrm{mL}$ ). During the ophthalmological examination, herpes simplex keratitis was detected in the right eye of the patient; she had erythema in the right eye starting at 10 months of age. In addition, the ophthalmological examination displayed nephelion, hypermetropia, astigmatism, and esotropia.

The physical examination of the patient revealed micrognathia, high-arched palate, short frenulum, flattened nasal root, flat philtrum, anteverted nares, broad nasal bridge, upslanting palpebral fissure, strabismus, flattened midface, telecanthus, hypertelorism, epicanthal folds, sparse eyebrows, mongolian spot, low nape hairline, prominent antihelix, prominent antitragus, widely spaced nipples, overlapping toes, and rocker bottom. During the dermatological examination, café-au-lait spots and light-colored spots like vitiligo were detected, and they seemed to resemble spots that develop following an infection. In addition, the skin was very dry and had an ichthyotic appearance (Fig. 1).

\section{Cytogenetic Analysis}

Chromosomal analyses were performed on peripheral blood samples using conventional G-banding techniques (550-band res- olution). Analysis results were reported according to the International System for Human Cytogenomic Nomenclature [ISCN, 2016]. Cytogenetic analysis showed a 46,XX,r(18)(p11.31q21.31) karyotype (Fig. 2), whereas the karyotype of the parents appeared normal (46,XX and 46,XY).

\section{Microarray Analysis}

Peripheral blood samples obtained from the patient and her parents were analyzed with chromosomal microarray analysis (CMA) using the CytoScan ${ }^{\mathrm{TM}} 750 \mathrm{~K}$ array (Affymetrix, USA). Data analysis was carried out using Chromosome Analysis Suite 4.0.0.385 software (Affymetrix). CMA was performed as described by the manufacturer's instructions, in accordance with the guidelines of the International Standard Cytogenomic Array (ISCA) Consortium. CMA analysis demonstrated a $6.3-\mathrm{Mb}$ deletion at 18p11.32p11.31 (hg19, chr18:136,226_6,433,028) and a 21.9-Mb deletion at 18q21.31q23 (hg19, chr18:56,142,390_78,014,123). As the molecular and conventional cytogenetic analyses of parents were normal, it was suggested that the ring chromosome developed de novo.

\section{Discussion}

The umbilical cord normally contains 2 arteries and 1 vein. The most common anatomic anomaly of the umbilical cord is the single umbilical artery. The following mechanisms were considered responsible for its development: (1) primary agenesis, (2) secondary atrophy or atresia, and (3) persistence of the original allantoic artery of the body stalk [Geipel et al., 2000]. It is believed that secondary atrophy may emerge in one of the umbilical arteries due to gender, ethnicity, multiple pregnancies, and maternal complications such as advanced maternal age, cigarette smoking, diabetes, hypertension, and epilepsy. The single umbilical artery due to primary agen- 


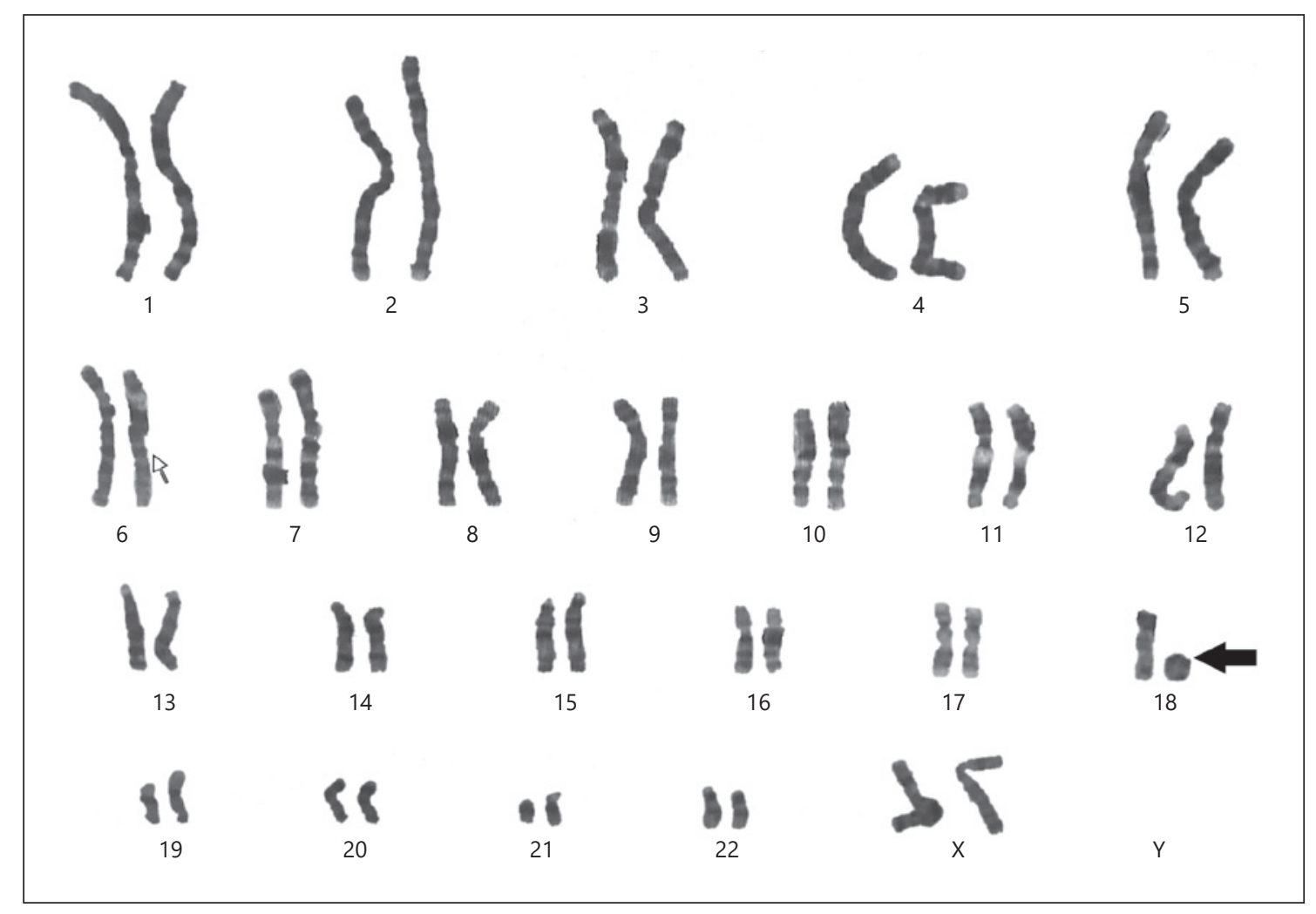

Fig. 2. Metaphase chromosomes obtained from stimulated peripheral blood lymphocytes. GTG-banded karyotype showing the presence of ring chromosome 18: 46,XX,r(18)(p11.31q21.31). Arrow indicates the ring chromosome.

esis has been associated with congenital fetal malformations and chromosomal anomalies [Catanzarite et al., 1995; Wiechec et al., 2016; Abdelazim et al., 2019]. Abdelazim et al. [2019] claimed that single umbilical artery can be considered a marker of diagnosable congenital fetal malformation and aneuploidy. Cantanzarite et al. [1995] determined aneuploidy by karyotype analysis of amniocentesis and cordocentesis materials in 10 of 82 fetuses with a sonographically detected 2 -vessel cord. Multiple anomalies were determined in 8 of these fetuses, trisomy 21 , mild polyhydramnios and bilateral hydronephrosis in 1 fetus, and 46,XY,del(4)(p13) karyotype, symmetrical intrauterine growth restriction and oligohydramnios in another one. Wiechec et al. [2015] suggested that when the first trimester pattern of trisomy 18 is considered, single umbilical artery and other ultrasonographic findings of aneuploidy should be specifically searched for. Furthermore, Wiechec et al. [2016] also argued that ultrasound-based screening was an effective alternative for trisomy 18 screening using traditional combined screening testing and emphasized the importance of ultrasound-based screening for trisomy 18. In this study, we emphasize the association of single umbilical artery and $\mathrm{r}(18)$ syndrome. Similarly, Mello et al. [2008] reported that a patient with a single umbilical artery during prenatal period was diagnosed with mosaic ring chromosome 18 and monosomy 18. Furthermore, van der Veken et al. [2010] reported that a 24-yearold male patient with multiple congenital abnormalities had a unique supernumerary ring chromosome 18 in $13 \%$ of his cells. The association of single umbilical artery and mosaic ring chromosome 18 has been reported in previous studies [Mello et al., 2008; van der Veken et al., 2010]. However, this study is the first to show the association of non-mosaic ring chromosome 18 with single umbilical artery.

Patients with $\mathrm{r}(18)$ may exhibit clinical characteristics found in patients with $18 \mathrm{p}$ deletion syndrome, $18 \mathrm{q}$ deletion syndrome, or both syndromes. Clinical characteristics of patients with $\mathrm{r}(18)$ may vary to a great extent depending on the size of chromosome deletion, the stability of the rings, the presence of aneuploidy cell lines, and 
the occurrence of mosaicism. The genotype-phenotype correlation is difficult to analyze due to the rare occurrence of $r(18)$. Feenstra et al. [2007] determined short stature in 15 of 29 patients with 18q deletion and associated short stature with 3 regions of deletion overlap, including the regions 18q12.1q12.3 (25.2-42.9 $\mathrm{Mb})$, 18q21.32q21.33 (58.5-61.3 Mb), and 18q22.3q23 (67.7$74.9 \mathrm{Mb}$ ). In addition, they associated the deletion at band 18q21.33 with microcephaly. Ohkubo et al. [2012] reported that a case with $\mathrm{r}(18)$ syndrome was a small boy (height: $93 \mathrm{~cm},-5.3 \mathrm{SD}$; weight: $13.3 \mathrm{~kg}$, 3rd percentile, and head circumference: $47 \mathrm{~cm},-3.3 \mathrm{SD}$ ). The height and head circumference of the present patient was 10-25th percentiles. The MRI findings of the cerebral anomalies encountered in patients with $\mathrm{r}(18)$ were reported in previous studies and were found to be similar to the findings of patients with 18q syndrome. Anzai et al. [2016] followed a patient with $\mathrm{r}(18)$ and determined mild symmetrical T2 hyperintensity in the white matter of the 15-month-old patient during the MRI examination. They found focal cystic lesions emerged in the periventricular white matter at age 11 and detected patchy lesions in MRI at age 14. Spreiz et al. [2013] conducted a study on 9 patients with $\mathrm{r}(18)$ and found a deletion in the transforming growth factor-beta-induced factor gene (TGIF; 602630) at $18 \mathrm{p} 11.31$ in 4 patients, and 2 of 5 patients had dysmyelination. Anzai et al. [2016] demonstrated that the neuroimages might change with time and suggested that the myelin basic protein gene $(M B P$, 159430) and neighboring genes were important in the process of hypomyelination. The MBP and TGIF1 genes were deleted in the present patient. However, the girl had benign external hydrocephaly in the MRI examination at the age of 2 months. Obviously, neuroimaging is necessary for the follow-up of the development of possible morbidities in advanced ages. Previous studies suggested that $\mathrm{r}(18)$ might be related to autoimmune disorders. Jain et al. [2011] suggested that $r(18)$ played a role in the autoimmune process and was related to thyroid disorders, type 1 diabetes mellitus, vitiligo, and IgA deficiency. Thus, patients with $\mathrm{r}(18)$ should be closely followed for endocrine problems. The present case had hypothyroidism which was reversed with thyroxine treatment; however, the blood glucose levels of the patient were in normal ranges. In previous studies [Ohkubo et al., 2012; Yao et al., 2016; Chau et al., 2017], hypothyroidism was detected in cases with $\mathrm{r}(18)$, while Jain et al. [2011] reported a case of r(18) with hyperthyroidism. The genes involved in the development of autoimmune disease in the cases of chromosome 18 abnormalities are still not well defined. Identification of these genes that have a role in autoimmune disease development helps to further understand the connection between genotypes and phenotypes. The IgG, IgM and IgA levels were low and frequent infections were reported in the medical history of the patient. Similarly, IgA deficiency was described previously in patients with $\mathrm{r}(18)$ [Ohkubo et al., 2012; Spreiz et al., 2013; Chau et al., 2017]. On the other hand, Yao et al. [2016] reported a slightly increased IgA level in a Chinese young girl with $\mathrm{r}(18)$. As of yet, no specific genes or regions in chromosome 18 have been specifically linked to IgA deficiency. Carter et al. [2015] suggested that individuals with $\mathrm{r}(18)$ who had teashirt zinc finger homeobox 1 gene $(T S H Z 1 ; 614427)$ deletion at $18 \mathrm{q}$ might have a high risk of congenital aural atresia compared to the other individuals in the society. Spreiz et al. [2013] reported that one of their patients had narrow external auditory canals and none of them had aural atresia. The present patient, whose TSHZ1 gene was deleted, had narrow external auditory canals and hearing loss. Atrial septal defect was detected in patients with $\mathrm{r}(18)$ [Palmer et al., 1967; Carter et al., 2015]. In addition, pulmonary stenosis [Carter et al., 2015; Anzai et al., 2016], aortic stenosis [Ohkubo et al., 2012], and patent ductus arteriosus [Carter et al., 2015] were also determined in these patients. The present patient had an atrial septal defect, patent ductus arteriosus, pulmonary hypertension, and dilatation in the ascending aorta.

In conclusion, ring chromosomes are rare anomalies and manifest different phenotypic findings depending on the loss of the genetic material. In the case that an intrauterine single umbilical artery is determined, a detailed ultrasonographic examination should be performed to check the presence of related anomalies. In the case of additional anomalies, fetal karyotyping may enable the early diagnosis and clinical characterization of even rare syndromes such as ring chromosomes. Furthermore, it may facilitate the early treatment or followup of endocrine and autoimmune disorders as well as other disorders. An increase in the number of case reports focused on these rare syndromes will contribute to the understanding of the unknown issues.

\section{Acknowledgement}

I would like to thank the family for participating in this study. I would like to also thank the Duzen Laboratory Group for karyotype and microarray data analyses. 


\section{Statement of Ethics}

Informed consent for genetic analysis and publication of clinical reports and photographs were obtained from the patient's parents in compliance with the national ethics regulation.

\section{Conflict of Interest Statement}

The author has no conflicts of interest to disclose.

\section{Funding Sources}

No specific funding was obtained from any agency or organization for the current study.

\section{Author Contributions}

N.E. drafted the manuscript in its entirety.

\section{References}

Abdelazim IA, Abu-Faza M, Hamed MES, Amer OO, Shikanova S, Zhurabekova G. Prenatal diagnosis of single umbilical artery complicated by intrauterine growth retardation and preterm labor: Case report. J Family Med Prim Care. 2019;8(6):2151-4.

Anzai M, Arai-Ichinoi N, Takezawa Y, Endo W, Inui $\mathrm{T}$, Sato R, et al. Patchy white matter hyperintensity in ring chromosome 18 syndrome. Pediatr Int. 2016;58(9):919-22.

Caba L, Rusu C, Plăiaşu V, Gug G, Grămescu M, Bujoran C, et al. Ring autosomes: some unexpected findings. Balkan J Med Genet. 2012; 15(2):35-46.

Carreira IM, Mascarenhas A, Matoso E, Couceiro AB, Ramos L, Dufke A, et al. Three unusual but cytogenetically similar cases with up to five different cell lines involving structural and numerical abnormalities of chromosome 18. J Histochem Cytochem. 2007;55(11): 1123-8.

Carter E, Heard P, Hasi M, Soileau B, Sebold C, Hale DE, et al. Ring 18 molecular assessment and clinical consequences. Am J Med Genet A. 2015;167A(1):54-63.

Catanzarite VA, Hendricks SK, Maida C, Westbrook C, Cousins L, Schrimmer D. Prenatal diagnosis of the two-vessel cord: implications for patient counselling and obstetric management. Ultrasound Obstet Gynecol. 1995;5(2): 98-105.

Chau A, Ramesh KH, Jagannath $\mathrm{AD}$, Arora S. Rheumatoid arthritis in an adult patient with mosaic distal 18q-, $18 \mathrm{p}$ - and ring chromosome 18. F1000Res. 2017;6:1940

Dacou-Voutetakis C, Sertedaki A, ManiatisChristidis M, Sarri C, Karadima G, Petersen $\mathrm{MB}$, et al. Insulin dependent diabetes mellitus (IDDM) and autoimmune thyroiditis in a boy with a ring chromosome 18: additional evidence of autoimmunity or IDDM gene(s) on chromosome 18. J Med Genet. 1999;36(2): $156-8$.

Feenstra I, Vissers LE, Orsel M, van Kessel AG, Brunner HG, Veltman JA, et al. Genotypephenotype mapping of chromosome 18q deletions by high-resolution array CGH: an update of the phenotypic map. Am J Med Genet A. $2007 ; 143 \mathrm{~A}(16): 1858-67$.

Geipel A, Germer U, Welp T, Schwinger E, Gembruch U. Prenatal diagnosis of single umbilical artery: determination of the absent side, associated anomalies, Doppler findings and perinatal outcome. Ultrasound Obstet Gynecol. 2000;15(2):114-7.

Gropp A, Jussen A, Ofteringer K. Multiple congenital anomalies associated with a partially ring-shaped chromosome probably derived from chromosome No. 18 in man. Nature. 1964;202:829-30.

ISCN 2016. An International System for Human Cytogenomic Nomenclature; McGowan-Jordan J, Simons A, Schmid M (eds). Cytogenet Genome Res 2016;149:1-140.

$\mathrm{Hu}$ Q, Chai H, Shu W, Li P. Human ring chromosome registry for cases in the Chinese population: re-emphasizing cytogenomic and clinical heterogeneity and reviewing diagnostic and treatment strategies. Mol Cytogenet. 2018;11:19.

Jacobs PA, Frackiewicz A, Law P, Hilditch CJ, Morton NE. The effect of structural aberrations of the chromosomes on reproductive fitness in man. II. Results. Clin Genet. 1975;8(3): 169-78.

Jain N, Reitnauer PJ, Rao KW, Aylsworth AS, Calikoglu AS. Autoimmune polyendocrinopathy associated with ring chromosome 18 . J Pediatr Endocrinol Metab. 2011;24(9-10): 847-50.

Kosztolányi G. The genetics and clinical characteristics of constitutional ring chromosomes. J Assoc Genet Technol. 2009;35(2):44-8.

Lo-Castro A, El-Malhany N, Galasso C, Verrotti A, Nardone AM, Postorivo D, et al. De novo mosaic ring chromosome 18 in a child with mental retardation, epilepsy and immunological problems. Eur J Med Genet. 2011;54(3): 329-32

Mazzaschi RL, Love DR, Hayes I, George A. Inheritance of a Ring Chromosome 21 in a Couple Undergoing In Vitro Fertilization (IVF): A Case Report. Case Rep Genet. 2011;2011: 158086.

Mello AL, Crotwell PL, Flanagan JD, Woltanski AR, Keppen LD, Van Eerden P, et al. Clinical course of a 20-month-old child diagnosed prenatally with mosaic ring chromosome 18 and monosomy 18. S D Med. 2008;61(9):327-31.

Ohkubo K, Ihara K, Ohga S, Ishimura M, Hara T. Hypothyroidism and levothyroxine-responsive liver dysfunction in a patient with ring chromosome 18 syndrome. Thyroid. 2021; 22(10):1080-3.
Palmer CG, Fareed N, Merritt AD. Ring chromosome 18 in a patient with multiple anomalies. J Med Genet. 1967;4(2):117-23.

Pezzolo A, Gimelli G, Cohen A, Lavaggetto A, Romano C, Fogu G, et al. Presence of telomeric and subtelomeric sequences at the fusion points of ring chromosomes indicates that the ring syndrome is caused by ring instability. Hum Genet 1993;92(1):23-27.

Rajesh H, Freckmann ML, Chapman M. Azoospermia and paternal autosomal ring chromosomes: case report and literature review. Reprod Biomed Online. 2011;23(4):466-70.

Rossi E, Riegel M, Messa J, Gimelli S, Maraschio P, Ciccone R, et al. Duplications in addition to terminal deletions are present in a proportion of ring chromosomes: clues to the mechanisms of formation. J Med Genet. 2008;45(3):147-54.

Spreiz A, Guilherme RS, Castellan C, Green A, Rittinger O, Wellek B, et al. Single-nucleotide polymorphism array-based characterization of ring chromosome 18. J Pediatr. 2013; 163(4):1174-8.

Takenouchi T, Yagihashi T, Tsuchiya H, Torii C, Hayashi K, Kosaki R, et al. Tissue-limited ring chromosome 18 mosaicism as a cause of PittHopkins syndrome. Am J Med Genet A. 2012; 158A(10):2621-3.

van der Veken LT, Dieleman MM, Douben H, van de Brug JC, van de Graaf R, Hoogeboom AJ, et al. Low grade mosaic for a complex supernumerary ring chromosome 18 in an adult patient with multiple congenital anomalies. Mol Cytogenet. 2010;3:13.

Wiechec M, Knafel A, Nocun A, Matyszkiewicz A, Wiercinska E, Latała E. How effective is ultrasound-based screening for trisomy 18 without the addition of biochemistry at the time of late first trimester? J Perinat Med. 2015;44(2):149-59.

Wiechec M, Knafel A, Nocun A, Ludwin A, Ludwin I, Maczka M, et al. Screening for trisomy 18 using traditional combined screening vs. ultrasound-based protocol in tertiary center environment. J Matern Fetal Neonatal Med. 2016;30(15):1765-70.

Yao H, Yang C, Huang X, Yang L, Zhao W, Yin $\mathrm{D}$, et al. Breakpoints and deleted genes identification of ring chromosome 18 in a Chinese girl by whole-genome low-coverage sequencing: a case report study. BMC Med Genet. 2016;17(1):49. 